\title{
DEVELOPMENT OF A SIMPLE NONLINEAR SWITCHED RELUCTANCE MOTOR MODEL USING MEASURED FLUX LINKAGE DATA AND CURVE FIT
}

\author{
By: \\ W.M. Chan \\ W.F. Weldon
}

Annual Meeting, IEEE Industry Applications Society, New Orleans, Louisiana, U.S.A., October 5-9, 1997

$$
P N-300
$$

Center for Electromechanics

The University of Texas at Austin

PRC, Mail Code R7000

Austin, TX 78712

(512) 471-4496 


\title{
Development of a Simple Nonlinear Switched Reluctance Motor Model using Measured Flux Linkage Data and Curve Fit
}

\author{
Wei Min Chan and W. F. Weldon, Senior Member, IEEE, \\ UT Center for Electromechanics \\ PRC Building 133 MC R7000 \\ 10100 Burnet Road \\ Austin, TX 78758 USA \\ Phone (512) 471-6369 Fax (512) 471-0781 E-Mail: s508@apache.cem.utexas.edu \\ WWW: http://ccwf.cc.utexas.edu/ serlinal/
}

\begin{abstract}
This paper presents the formulation and simulation of a simple nonlinear switched reluctance motor (SRM) model. The model formulation is developed by first measuring the motor's flux linkage. A suitable 3 dimension shape function is developed to curve fit this data. Multiple shape functions are added together to reduce the mean square error of the flux linkage equation. We call this equation the Chan Series. Motor parameters such as inductance and back electromotive force coefficient equations are obtained by differentiating the Chan Series. The coenergy and motor torque equations are derived from the Chan Series by mathematical manipulation. Nonlinear model analysis is then carried out. Ways to indicate the motor size that takes into consideration the effect of magnetic flux saturation are proposed. Two motor relations are presented. Computer simulation of the model for chop, singlechop, and single-pulse modes are performed and compared to those published in [19]. The comparisons show that the developed model can predict the SRM behavior.
\end{abstract}

\section{INTRODUCTION}

Switched reluctance motors (SRMs) are the focus of much interest today. The motor design is simple: a rotor without windings and stator with windings located at the poles.[1] These features make the motor rugged and inexpensive to manufacture.[2] Also, SRMs are a less expensive alternative to permanent-magnet brushless motors in many applications.[3] Compared to induction motors, SRMs are more efficient and less costly.[4] SRMs have the potential to be used as variable speed drives in many commercial applications such as vehicles.[5]

SRM dynamics are nonlinear in nature.[6] The motor torque is a nonlinear function of the current magnitude and rotor position. The air gap reluctance between the salient stator and rotor poles varies with rotor position. Usually, these motors operate in the magnetic flux saturation region so that a higher torque to mass ratio is obtained.[7]

A nonlinear mathematical model of the SRM can provide a better insight into the motor dynamics. The model can be used to formulate speed and torque control algorithms. Using the model, motor efficiency can be evaluated. Eventually, such models can lead to better SRM designs.

Finite elements have been used to form a nonlinear model. Uematsu used finite element analysis to compute the coenergy of the motor for various current levels and rotor angles.[8] The flux linkage and motor torque are obtained by computing the slope of the coenergy with respect to current and rotor angle, respectively. This method is useful to design a SRM. However, more work will be needed to obtain the dynamic behavior of the motor.

A number of nonlinear SRM models have been developed using magnetics theory. Faiz used a magnetic circuit concept to compute the SRM's mean torque.[9] Moallem used an improved magnetic equivalent circuit method to predict the performance of the SRM.[10] Staton developed a unified theory of torque production in SRMs.[11] Also, Staton predicted the torque in a SRM using the flux-mmf diagram.[12] Radun developed analytical equations, which include the effect of iron saturation, to model the motor.[13] His equations can predict the machine performance, flux linkage, back electromotive force, and static torque. Other nonlinear SRM models have been developed by Filicori [14], Torrey [15], and Miller [16]. 
Neural networks have been used to predict the SRM's nonlinear behavior. Garside used application specific artificial neural networks to identify SRM states using odd periodic activation functions.[17] Belfore used evolutionary neural networks to develop a SRM model.[18] This model is composed of 4 hidden layers of $17,11,13$, and 16 neurons. His model shows good agreement to simulation results.

Panda presented an empirical SRM model in [19]. He used the cosine series to curve fit the flux linkage data. The obtained equation is differentiated to obtain the back electromotive force equation. Current rise and fall times are predicted using the curve fitted flux linkage equation, derived back electromotive force equation, and other derivatives of the flux linkage equation. Current rise and fall rates with respect to the rotor angle are predicted using the curve fitted flux linkage equation and its derivatives. These current rise and fall rates are used to plot the chop, single-chop, and singlepulse current wave forms as functions of rotor position.

Simple nonlinear SRM models are desired. Such models can be used in control algorithms such as: feedback linearization control in [20] and [21]; sliding mode control in [22]; robust control in [23], [24], and [25]; and adaptive control in [26]. Also, nonlinear models can be used in torque control as described in [27]. State observers can be developed from these models.[28] Also, simple nonlinear models can be used in the energy optimizing control strategy that is presented in [29].

A simple nonlinear SRM model is developed in this paper. The flux linkage used is that measured from a motor in [19]. A special shape function is used to curve fit this data. Curve fitting is done by use of the method of steepest descent.[30] The mean square error of the flux linkage equation is reduced by adding more than one shape function to the equation. We name this equation the Chan Series. Motor parameters such as inductance and back electromotive force coefficient are obtained by differentiating the Chan Series. The coenergy equation is formulated by integrating the Chan Series with respect to current. This coenergy equation is differentiated with respect to the SRM's rotor angle to obtain the motor's torque equation. Ways to indicate the size of the SRM that takes into account the effect of magnetic flux saturation is described. Two motor relations are presented. Computer simulation results are obtained and compared to those published in [19]. The comparisons show that the developed nonlinear model predicts the SRM's behavior.

This paper is composed of 5 sections: introduction, development of a simple nonlinear SRM model, nonlinear model analysis, computer simulation results, and conclusion.

\section{DEVELOPMENT OF A SIMPLE NONLINEAR SRM MODEL.}

\section{A. Model formulation}

The simple nonlinear SRM model is developed in this section. First the SRM's flux linkage is measured. Such an example is shown in Fig. 1.[19] This flux linkage set is measured by Panda from a $4 \mathrm{KW}$ SRM.

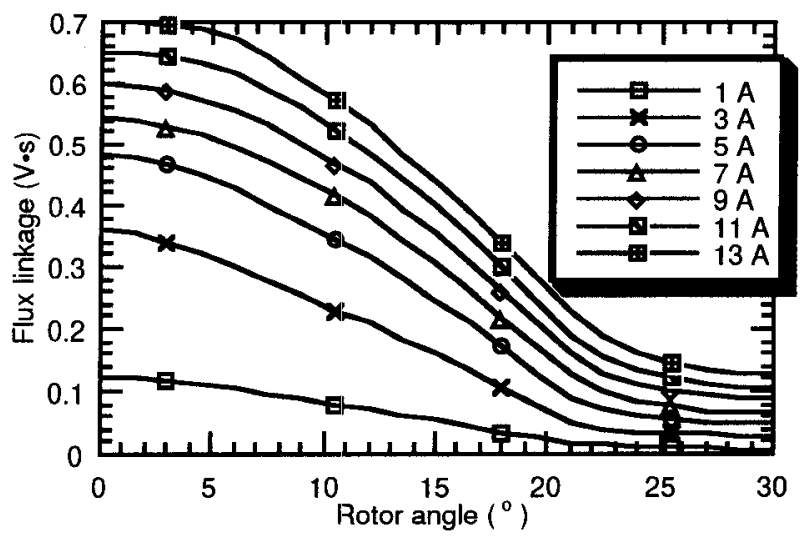

Fig. 1. Measured flux linkage of a one phase $4 \mathrm{KW} \mathrm{SRM} \mathrm{at} \mathrm{different}$ current levels and rotor positions.[19]

A suitable flux linkage equation must be found so that it can be curve fitted to the measured flux linkage data. This equation must have certain properties: (1) zero slope at the stator pole axis of symmetry, (2) symmetrical about the stator pole axis, (3) integrable with respect to current, and (4) differentiable with respect to rotor angle. We have developed such an equation and name it the Chan Series, see (1).

$$
\lambda(\theta, i)=\sum_{n=1}^{M} c_{0 n}\left[\frac{1}{1+e^{c^{1} n^{\theta-C} 2 n}}+\frac{1}{1+e^{-c_{1 n} \theta-c_{2 n}}}-c_{3 n}\right]\left[\frac{2}{1+e^{-c_{4 n} i}}-1\right]
$$

where $c_{1 n}, c_{2 n}, c_{3 n}$, and $c_{4 n}$ are constants. The stator current is $i$ and rotor angle is $\theta$. Integer $M$ is the number of such terms used to reduce the mean square error. Property 1 ensures that the motor torque is zero when both stator and rotor poles are aligned. Property 2 provides symmetrical electromagnetic characteristics. Property 3 allows the coenergy to be formulated by integrating the Chan Series with respect to the stator current, see (2).

For $0 \leq \mathrm{i}$ :

$$
\begin{aligned}
W(\theta, i)_{m}^{*} & =\int_{0}^{i} \lambda(\theta, i) d i \\
& =\int_{0}^{i} \sum_{n=1}^{M} c_{0 n}\left[\frac{1}{1+e^{c_{1 n}(\theta-c 2 n}}+\frac{1}{1+e^{-c_{1 n} \theta-c_{2 n}}}-c_{3 n}\right]\left[-\frac{2 e^{-c_{4 n} i}}{1+e^{-c_{4 n}^{i}}}+1\right] d i \\
& =\sum_{n=1}^{M} c_{0 n}\left[\frac{1}{1+e^{c_{1 n} \theta-c_{2 n}}}+\frac{1}{1+e^{-c_{1} n^{\theta-c} c_{2 n}}}-c_{3 n}\right]\left[\frac{2 \ln \left(1+e^{-c_{4 n}}\right)-2 \ln (2)}{c_{4 n}}+i\right]
\end{aligned}
$$


For $\mathrm{i}<0:$
$\begin{aligned} W(\theta, \mathrm{i})_{\mathrm{m}}^{*} & =\int_{-i}^{0} \lambda(\theta, i) d i \\ & =\sum_{n=1}^{M} c_{0 n}\left[\frac{1}{1+e^{c / n n^{\theta-c}}}+\frac{1}{1+e^{-c_{1 n} \theta-c_{2 n} n}}-c_{3 n}\right]\left[\frac{2 \ln (2)-2 \ln \left(1+e^{c_{4 n}}\right)}{c_{4 n}}+i\right]\end{aligned}$

Property 4 ensures that a motor torque equation that drives the SRM can be obtained by differentiating the coenergy equation with respect to the rotor angle, see (4). Proof that the motor torque can be formulated in this manner from the coenergy of a nonlinear system is provided in secondary section $B$.

For $0 \leq \mathrm{i}$ :

$$
\begin{aligned}
& T(\theta, i)=\frac{\partial W(\theta, i)_{m}^{*}}{\partial \theta}
\end{aligned}
$$

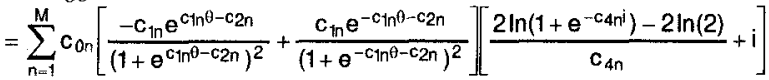

For $\mathrm{i}<0$ :

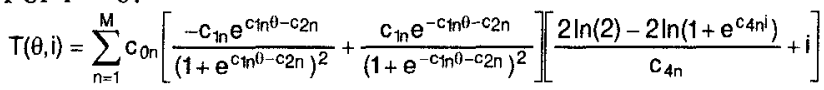

The above equation is valid when the rotor is polarized. However, the SRM rotor is made of soft iron that does not become magnetized. Thus, the equation below should be used.

For $\mathrm{i}<0$ :

$$
T(\theta, i)=-\sum_{n=1}^{M} c_{0 n}\left[\frac{-c_{n n} e^{c_{1 n} \theta-c_{2 n}}}{\left(1+e^{c_{1 n} \theta-c_{2 n}}\right)^{2}}+\frac{c_{\ln } e^{-c_{1 n} n^{\theta-c} c_{2 n}}}{\left(1+e^{-c_{1 n} \theta-c_{2 n}}\right)^{2}}\right]\left[\frac{2 \ln (2)-2 \ln \left(1+e^{c_{4 n} i}\right)}{c_{4 n}}+i\right]
$$

The Chan Series is curve fitted to the flux linkage data that is measured in [19]. Curve fitting is done by use of the method of steepest descent, which is described in [30] or [31]. The computed coefficients of the curve fitted 5 term Chan Series are:

$c_{01}=0.600236, c_{11}=26.050989, c_{21}=8.770479$,

$c_{31}=0.330620, c_{41}=0.055926$,

$\mathrm{c}_{02}=1.169206, \mathrm{c}_{12}=13.596735, \mathrm{c}_{22}=3.740967$,

$c_{32}=1.144212, c_{42}=0.801617$,

$c_{03}=-1.071243, c_{13}=12.107311, c_{23}=3.249941$,

$\mathrm{c}_{33}=1.273768, \mathrm{c}_{43}=0.970880$,

$\mathrm{c}_{04}=0.172338, \mathrm{c}_{14}=12.985381, \mathrm{c}_{24}=1.715012$,

$\mathrm{C}_{34}=1.377829, \mathrm{c}_{44}=1.004575$,

$\mathrm{c}_{05}=0.176827, \mathrm{c}_{15}=12.988520, \mathrm{c}_{25}=1.719679$,

$\mathrm{c}_{35}=1.381047, \mathrm{c}_{45}=1.004695$

The average error is 0.004025 . A plot of the curve fitted equation is shown in Fig. 2.

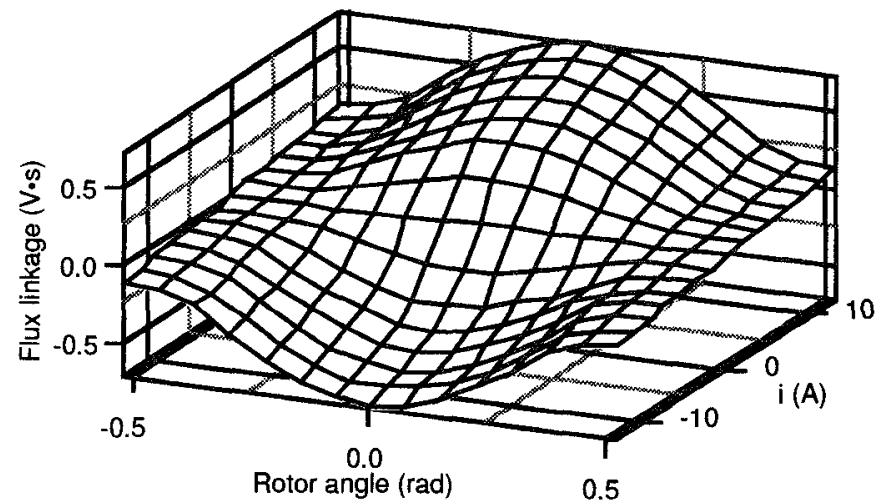

Fig. 2: A plot of the 5 term curve fitted Chan Series.

The current magnitude is related to the rotor position by a differential equation. This equation is formulated from the electric circuit of the stator coil, which is shown in Fig. 3.

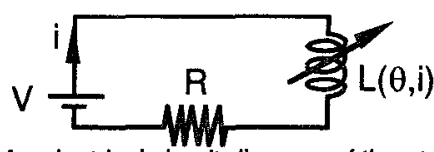

Fig. 3. An electrical circuit diagram of the stator coil.

The circuit's current is I and voltage is $V$. The coil has an inductance, $L(\theta, i)$, which is a function of the rotor position, $\theta$, and current, $i$. This coil has an internal resistance, $R$. The Kirchoff's voltage law is used to formulate the differential equation (7). The variable $\lambda$ is the flux linkage and $w$ is the angular velocity of the rotor.

$$
\begin{aligned}
V & =R i+\frac{\partial \lambda(\theta, i)}{\partial t}=R i+\frac{\partial \lambda(\theta, i)}{\partial i} \frac{\partial i}{\partial t}+\frac{\partial \lambda(\theta, i)}{\partial \theta} \frac{\partial \theta}{\partial t} \\
& =R i+L(\theta, i) \frac{\partial i}{\partial t}+E(\theta, i) w
\end{aligned}
$$

where $L(\theta, i)=\frac{\partial \lambda(\theta, i)}{\partial i}, E(\theta, i)=\frac{\partial \lambda(\theta, i)}{\partial \theta}$, and $w=\frac{\partial \theta}{\partial t}$.

Note that the value of $|E(\theta, i)|$ is called the back emf coefficient in [19]. Thus, the formulated equation is referred to as back emf coefficient equation. The Chan Series is used in (7) to complete the differential equation. The inductance and $E(\theta, i)$ equations are formulated by differentiating the Chan Series. These derivatives are shown in (8) and (9).

$$
\begin{aligned}
& L(\theta, i)=\sum_{n=1}^{M} c_{0 n}\left[\frac{1}{1+e^{c i n 0-c_{2 n} n}}+\frac{1}{1+e^{-c i n \theta-c 2 n}}-c_{3 n}\left[\frac{2 c_{4 n} e^{-c 4 a n i}}{\left(1+e^{-c 4 n}\right)^{2}}\right]\right.
\end{aligned}
$$

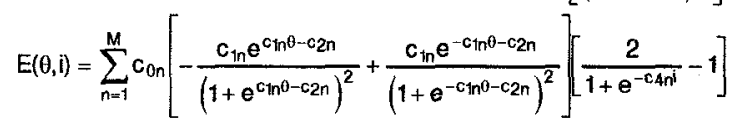

Plots of these 2 equations are shown in Figs. 4 and 5 , respectively. 


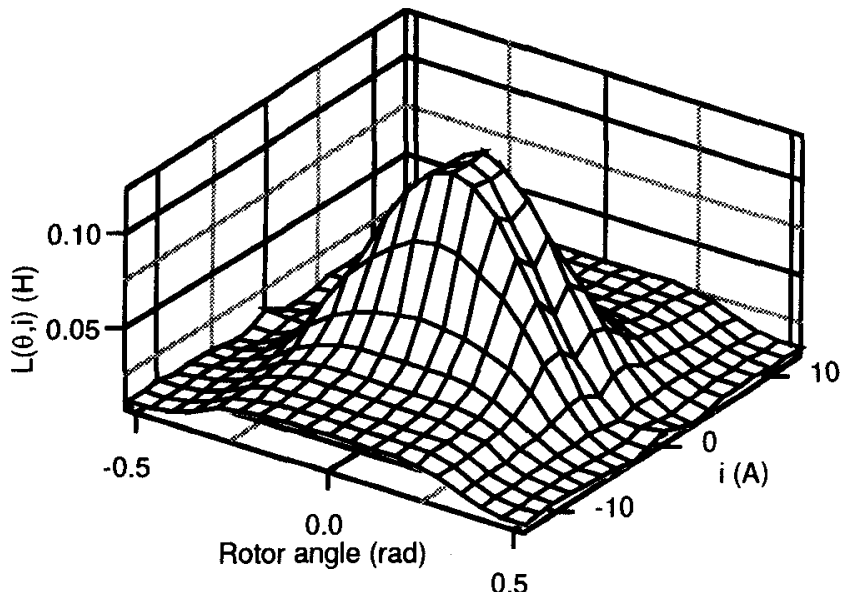

Fig. 4. Plot of the 5 term inductance equation that is a function of rotor position and current.

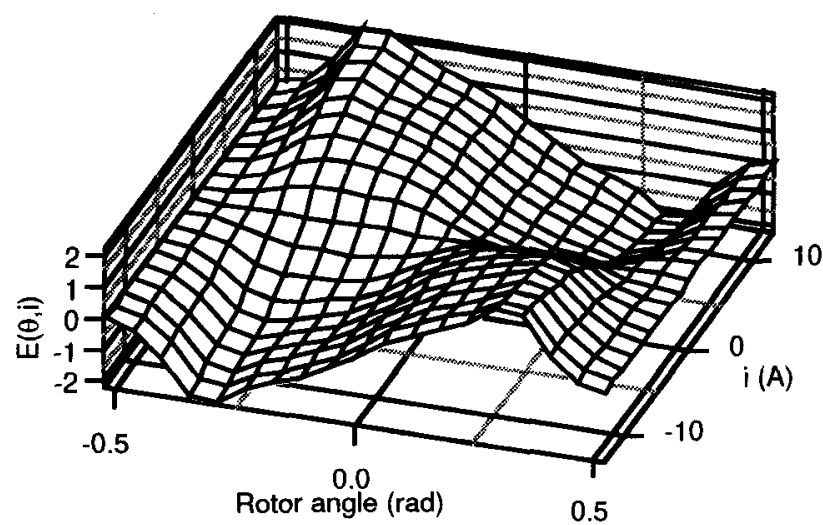

Fig. 5. A plot of the 5 term $E(\theta, i)$ equation that is a function of rotor position and current.

Using (4) and (6) the SRM's torque profile is plotted in Fig. 6 .

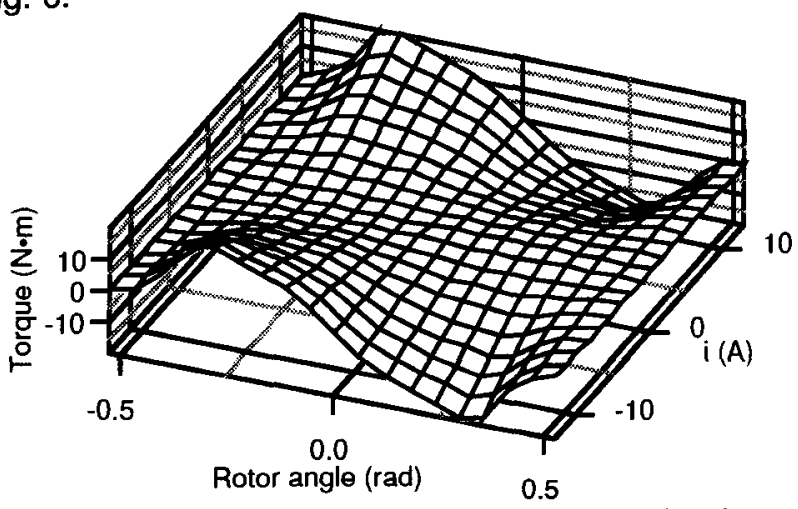

Fig. 6. A plot of the 5 term torque equation that is a function of rotor position and current.

The above equations make up a simple nonlinear SRM model. Using this model, analysis of the motor is performed and presented in Section III.
B. Proof that the motor torque can be computed from the coenergy of a nonlinear model

Proof that the motor torque can be computed from the coenergy of a nonlinear model is provided in this section. An invertible nonlinear equation that relates the flux linkage to the current is chosen, see (10).

$$
i=\frac{26.5 \lambda^{2}}{1+\theta+\theta^{2}}
$$

where $\theta$ is the rotor angle. Using this equation, the magnetic energy equation is derived as follows:

$$
W_{m}(\theta, \lambda)=\int \mathrm{i} d \lambda=\int \frac{26.5 \lambda^{2}}{1+\theta+\theta^{2}} d \lambda=\frac{\lambda^{3}}{3\left(1+\theta+\theta^{2}\right)}
$$

The torque equation is formulated by differentiating (11):

$$
T=-\frac{\partial W_{m}(\theta, \lambda)}{\partial \theta}=-\frac{\partial\left[\frac{26.5 \lambda^{3}}{3\left(1+\theta+\theta^{2}\right)}\right]}{\partial \theta}=\frac{26.5 \lambda^{3}(1+2 \theta)}{3\left(1+\theta+\theta^{2}\right)^{2}}
$$

Next, the motor torque is formulated from the coenergy equation. Mapping of the flux linkage to current in (10) is rearranged to obtain a relation of flux linkage in terms of current.

$$
\lambda=0.194257\left(1+\theta+\theta^{2}\right)^{\frac{1}{2}} i^{\frac{1}{2}}
$$

Using (13), the coenergy equation is developed as follows:

$$
W_{m}^{*}=\int \lambda d i=\int 0.194257\left(1+\theta+\theta^{2}\right)^{\frac{1}{2}} i^{\frac{1}{2}} \mathrm{di}=0.194257 \frac{2}{3}\left(1+\theta+\theta^{2}\right)^{\frac{1}{2}} i^{\frac{3}{2}}
$$

The torque equation is formulated by differentiating the coenergy equation.

$$
\left.T=\frac{\partial W_{m}^{*}(\theta, i)}{\partial \theta}=0.194257 \frac{1}{3}\left(1+\theta+\theta^{2}\right)^{-\frac{1}{2}}(1+2 \theta)\right)^{\frac{3}{2}}
$$

Equation (10) is put into Equation (15) to obtain a motor torque equation that is a function of both rotor angle and flux linkage.

$$
T=0.194257 \frac{1}{3}\left(1+\theta+\theta^{2}\right)^{-\frac{1}{2}}(1+2 \theta)\left[\frac{26.5 \lambda^{2}}{\left(1+\theta+\theta^{2}\right)}\right]^{\frac{3}{2}}=\frac{26.5(1+2 \theta) \lambda^{3}}{3\left(1+\theta+\theta^{2}\right)^{2}}
$$

Comparing (16) to (12), we see that both motor torque equations are identical. Thus, the motor torque can be computed from the coenergy of a nonlinear model.

\section{NONLINEAR MODEL ANALYSIS.}

\section{A. Relations Between Formulated Equations}

This section presents certain relations that exist between equations of the nonlinear SRM model. Relation between the inductance, back emf coefficient, and flux linkage equations is shown in (17).

$$
\int L(\theta, i) d i=\int E(\theta, i) d \theta=\lambda(\theta, i)
$$

Using (17), the volume under the inductance surface is shown to be equal to the integral of the flux linkage equation in (18). This volume indicates the overall strength of the magnetic field at a given current level 
and range of rotor angle, taking into account the effect of magnetic flux saturation. Note that the size of the SRM can be indicated based on the overall strength of the magnetic field. The computed volume under the inductance surface for the motor is $0.221 \mathrm{HA}$ (Henry Ampere).

$$
\iint L(\theta, i) d i d \theta=\int \lambda(\theta, i) d \theta
$$

Likewise, the volume under the back emf coefficient surface equals the coenergy:

$$
\iint E(\theta, i) d \theta d i=\int \lambda(\theta, i) d i=w(\theta, i)^{*}
$$

The relation between (17) and (18) is obtained by integrating the inductance equation in (17) and back emf coefficient equation in (18) once more as shown in (20) and (21), respectively.

$$
\begin{gathered}
\iiint L(\theta, i) d i d \theta d i=\iint \lambda(\theta, i) d \theta d i \\
\iiint E(\theta, i) d \theta d i d \theta=\iint \lambda(\theta, i) d i d \theta=\int W(\theta, i)^{*} d \theta
\end{gathered}
$$

Equations (20) and (21) are equal to each other because they represent the volume under the flux linkage curve. Also the volume under the flux linkage surface equals the integral of the coenergy with respect to the rotor angle, see (21). This relation shows that the volume under the flux linkage surface indicates the energy level at a given current level over the range of rotor position, considering the effect of magnetic flux saturation. Thus, the size of the SRM can be indicated based on this volume. The computed volume under the flux linkage surface of the motor is $1.775 \mathrm{WbA}$ (Weber Ampere).

When the inductance and back emf coefficient equations are triple integrable, such as those derived from the Chan Series, then (22) can be shown to be true. This inductance emf flux linkage motor relation is proved in secondary section B by use of the Chan Series. The significance of this relation is it links the 3 motor parameters.

$$
\iiint L(\theta, i) d i d \theta d i=\iiint E(\theta, i) d \theta d i d \theta=\iint \lambda(\theta, i) d i d \theta
$$

Using (4), and (19) the relation between the torque and coenergy equations is shown below.

$$
\int T(\theta, i) d \theta=\iint E(\theta, i) d \theta d i
$$

Fubini's Theorem states that the order of integration in the double integral of $E(\theta, i)$ does not affect the value of the integral.[32] Thus, (23) can be expressed as

$$
\frac{d T(\theta, i)}{d i}=-E(\theta, i)
$$

Note that a negative sign is placed in front of the $E(\theta, i)$ equation in (24). The reason is the $E(\theta, i)$ equation represents electricity generated by the motor torque. This torque emf motor relation is shown to be true by differentiating (4) to obtain the negative of (9). The significance of this motor relation is it links the mechanical motion to the generated electricity in practice, this relation is useful because the motor torque can be measured, curve fitted, and differentiated to obtain the back emf coefficient equation.

The motor's size, taking into consideration the effects of magnetic flux saturation, can be indicated by the volume under the coenergy surface. The computed volume under the coenergy surface of the motor is $8.66 \mathrm{JA}$ (Joule Ampere).

\section{B. Proof of the inductance emf flux linkage motor relation}

The inductance emf flux linkage motor relation shown in (22) is proved by use of the Chan Series. The volume under the flux linkage surface is:

$\iint \lambda(\theta, i) d i d \theta$

$=\iint \sum_{n=1}^{M} c_{0 n}\left[\frac{1}{1+e^{c_{1 n} n^{\theta-c_{2 n}}}}+\frac{1}{1+e^{-c 1 n^{\theta-c} c_{2 n}}}-c_{3 n}\right]\left[2\left(1-\frac{e^{-c_{4 n} i}}{1+e^{-c_{4 n} i}}\right)-1\right] d i d \theta$

$=\sum_{n=1}^{M}\left\{c_{0 n}\left[-\frac{\ln \left(1+e^{c_{n n}\left(\theta-c_{2 n}\right.}\right)}{c_{t n}}+\frac{\ln \left(1+e^{\left.-c_{1 n} 0-c_{2 n}\right)}\right.}{c_{\text {tn }}}+\left(2-c_{3 n}\right) \theta+a_{12}\right]\right.$

$\left.\left[\frac{2 \ln \left(1+e^{-c 4 n i}\right)}{c_{4 n}}+i+a_{11}\right]\right\}$

where $a_{11}$ and $a_{12}$ are integration constants.

$\iiint L(\theta, i) d i d \theta d i$

$=\iint \sum_{n=1}^{M} c_{0 n}\left[\frac{1}{1+e^{c_{1 n} \theta-c_{2 n}}}+\frac{1}{1+e^{-c_{1 n} \theta-c_{2 n}}}-c_{3 n}\right]\left[\frac{2}{1+e^{-c_{4 n}}}+a_{21}\right] d \theta d i$

$=\sum_{n=1}^{M}\left\{c_{0 n}\left[-\frac{\ln \left(1+e^{c_{1 n} \theta-c_{2 n}}\right)}{c_{n n}}+\frac{\ln \left(1+e^{-c_{1 n} \theta-c_{2 n}}\right)}{c_{n n}}+\left(2-c_{3 n}\right) \theta+a_{22}\right]\right.$

$\left.\left[\frac{2 \ln \left(1+e^{-c_{4 n} i}\right)}{c_{4 n}}+\left(2+a_{21}\right) i+a_{23}\right]\right\}$

where $a_{21}, a_{22}$, and $a_{23}$ are integration constants. The computed value of $(26)$ equals the volume under the flux linkage surface equation when $a_{22}=a_{12}, a_{21}=-1$, and $a_{23}=a_{11}$.

$\iiint E(\theta, i) d \theta d i d \theta$

$=\iint \sum_{n=1}^{M} c_{0 n}\left[\frac{1}{1+e^{c 1 n^{0}-c_{2 n}}}+\frac{1}{1+e^{-c+n n^{\theta-c}-2 n}}+a_{31}\right]\left[2\left(1-\frac{e^{-c 4 n i}}{1+\theta^{-c 4 n i}}\right)-1\right] d i d \theta$

$=\sum_{n=1}^{M}\left\{c_{0 n}\left[-\frac{\ln \left(1+e^{\left.c_{\ln n} 0-c_{2 n}\right)}\right.}{c_{1 n}}+\frac{\ln \left(1+e^{\left.-c_{1 n} 0-c_{2 n}\right)}\right.}{c_{1 n}}+\left(2+a_{31}\right) \theta+a_{33}\right]\right.$

$\left.\left[\frac{2 \ln \left(1+e^{-c_{4 n} i}\right)}{c_{4 n}}+i+a_{32}\right]\right\}$

where $a_{31}, a_{32}$, and $a_{33}$ are integration constants. The computed value of (27) equals the volume under the flux linkage surface equation when $a_{31}=-c_{3 n}, a_{33}=a_{12}$, and $\mathrm{a}_{32}=\mathrm{a}_{11}$.

Thus, the inductance emf flux linkage motor relation, shown in (22), is proved because (25), (26), and (27) are equal to one another.

\section{COMPUTER SIMULATION RESULTS.}


A model of the active phase stator coil's current dynamics is formulated by rearranging ( 7$)$ as follows:

$$
\begin{aligned}
L(\theta, i) \frac{\partial i}{\partial t} & =V-R i-E(\theta, i) w \\
\frac{\partial i}{\partial t} & =\frac{V}{L(0, i)}-\frac{R}{L(0, i)} i-\frac{E(\theta, i)}{L(\theta, i)} w
\end{aligned}
$$

When provided with initial conditions, this nonlinear differential equation can be solved numerically for current values in the subsequent time steps. Using the 4th order Runga Kutta routine, computer simulations of the current dynamics in the stator coil for chopping, single-chop, and single-pulse modes are obtained. These results (model) are shown in Figs. 7, 8, and 9, respectively. Also, plots of current values (data) predicted in [19] are superimposed onto these figures. The plots show that both data sets are in good agreement with one another.

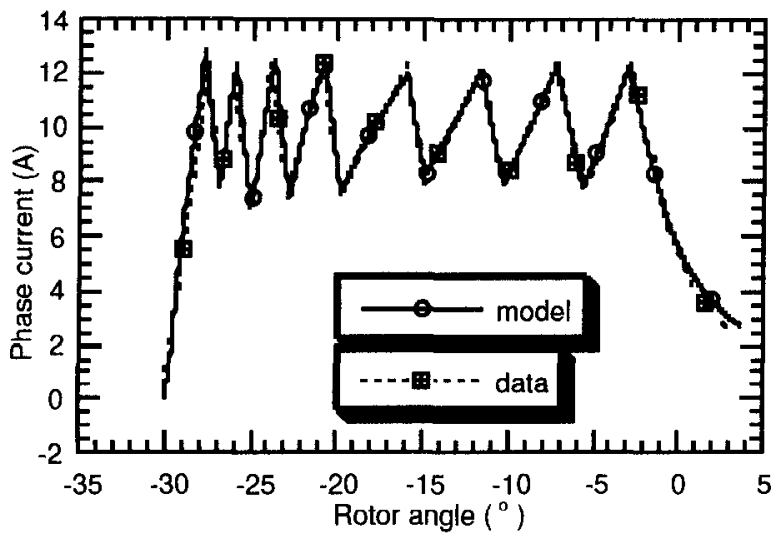

Fig. 7. Stator current in the chopping mode at $700 \mathrm{r} / \mathrm{min}$ and $500 \mathrm{~V}$.

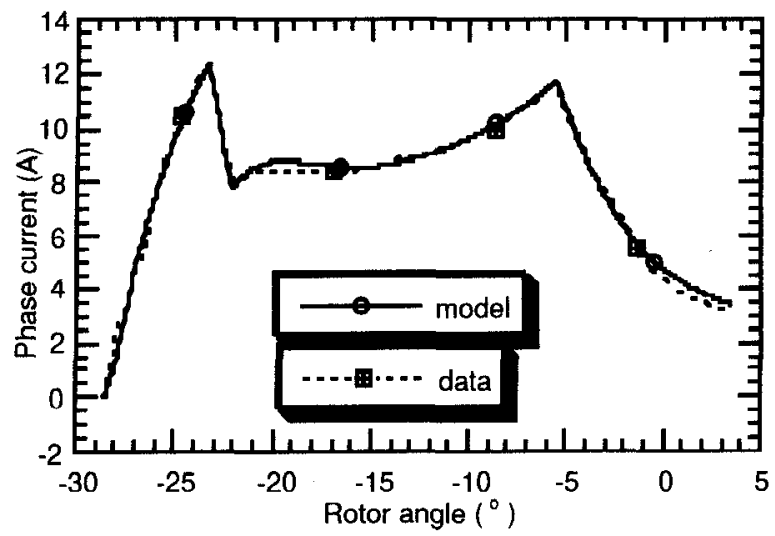

Fig. 8. Stator current in the single-chop mode at $1300 \mathrm{r} / \mathrm{min}$ and $500 \mathrm{~V}$.

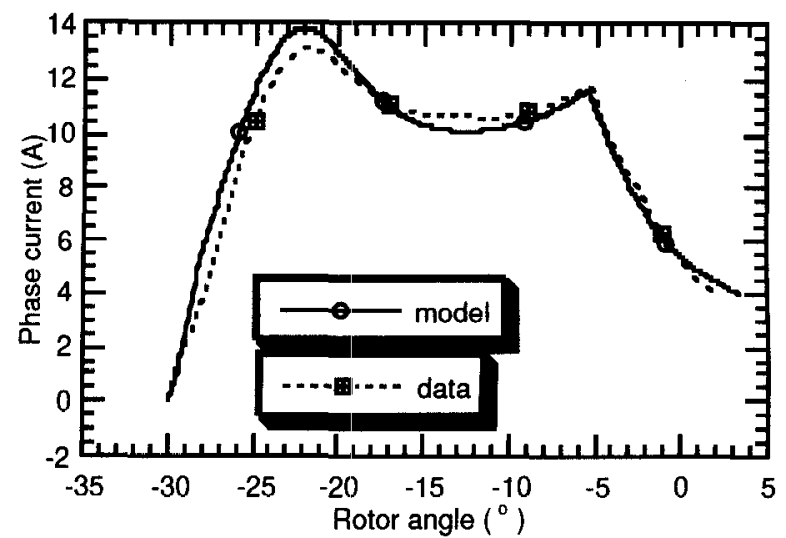

Fig. 9. Stator current in the single-pulse mode at $1500 \mathrm{r} / \mathrm{min}$ and $500 \mathrm{~V}$.

The validity of the simple nonlinear model is tested by use of another set of operating condition: chopping mode with rotor speed at $600 \mathrm{r} / \mathrm{min}$ and voltage limit of $440 \mathrm{~V}$. Computer simulation results (model) and that (data) obtained in [19] are plotted in Fig. 10. The plot shows good agreement between the two data sets.

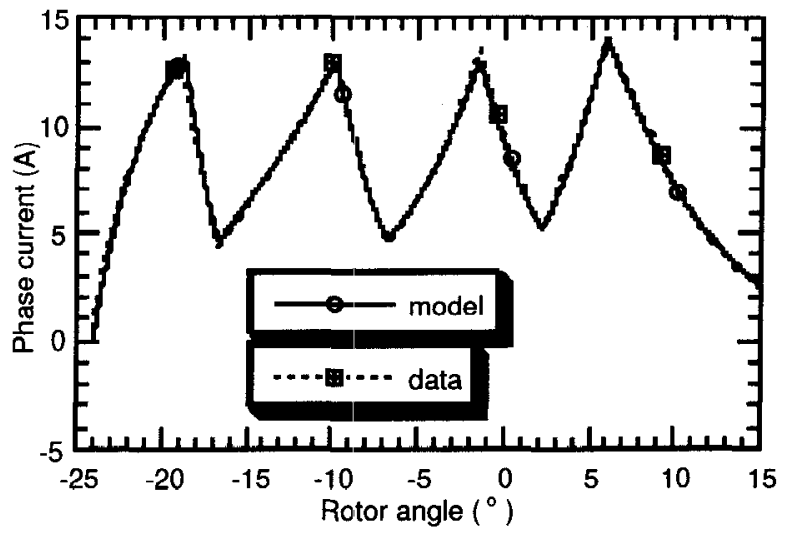

Fig. 10. Stator current in the chopping mode at $600 \mathrm{r} / \mathrm{min}$ and $440 \mathrm{~V}$.

The torque equations (4) and (6) are used to compute the torque values in the chopping mode with the rotor speed at $900 \mathrm{r} / \mathrm{min}$ and voltage limit of $500 \mathrm{~V}$. Plots of both chop current and torque profiles (model) are shown in Fig. 11. Superimposed on this figure are the chop current and torque profiles (data) predicted in [19]. Both sets of data show good agreement to one another. 

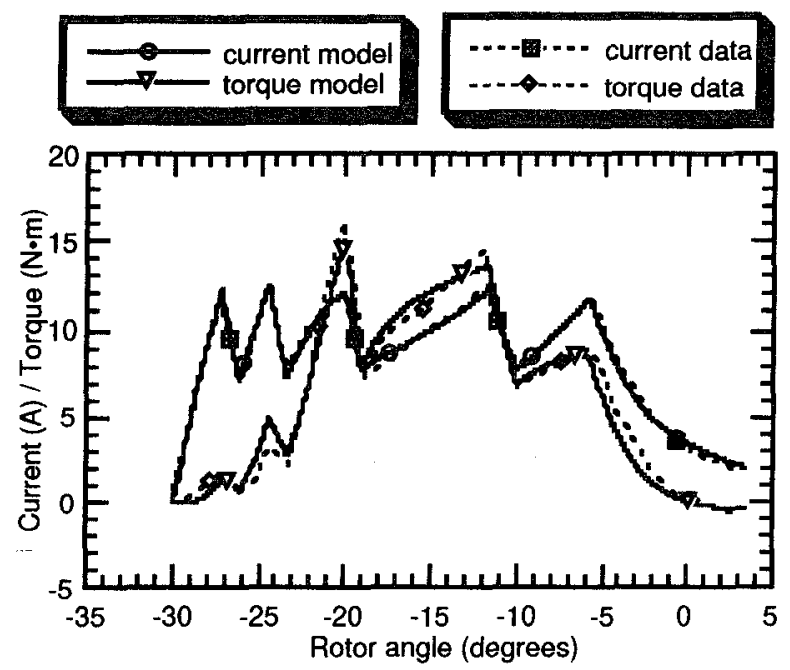

Fig. 11. Stator current and torque profiles in the chopping mode at 900 $\mathrm{r} / \mathrm{min}$ and $500 \mathrm{~V}$.

Panda measured the static torque values (data) of the motor at various current levels and rotor position.[19] A plot of this measured data together with those predicted by Panda's model (Panda) are shown in Fig. 12. Using the torque equations (4) and (6), the computed torque values (model) of the simple nonlinear model are also plotted on the same figure. The figure shows good agreement of the torque values between the model and data.

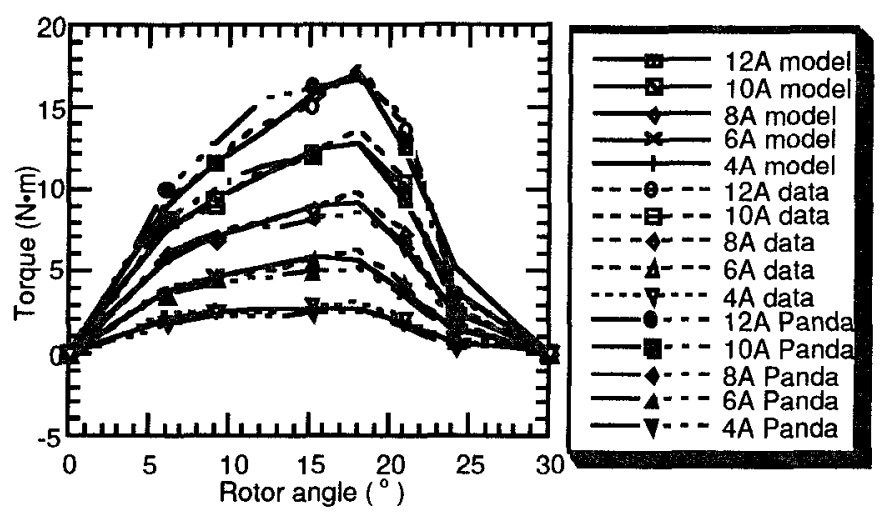

Fig. 12. Comparison of static torque profiles at various current levels.

\section{CONCLUSION.}

A simple nonlinear SRM model has been developed using flux linkage data that is measured from the SRM and curve fit. A special 3 dimension shape function has been developed to curve fit this data. A few of these shape functions are added together to reduce the mean square error. This equation is called the Chan Series. A 5 term Chan Series is curve fitted to the flux linkage data using the method of steepest descent.
The computed average error is 0.004025 . Other motor equations are obtained by mathematically manipulating the Chan Series: $L(\theta, i), E(\theta, i)$, and torque. Also, 3 dimensional plots of these equations are presented.

Analysis of the nonlinear model revealed the following. Volume under the inductance surface indicates the overall strength of the magnetic field at a given current level and range of rotor angle, taking into consideration the effect of magnetic flux saturation. The computed volume under the inductance surface of the motor is $0.221 \mathrm{HA}$. Volume under the flux linkage surface indicates the energy level at a given current level over the range of rotor position considering the effect of magnetic flux saturation. The computed volume under the flux linkage surface of the motor is $1.775 \mathrm{WbA}$. Two motor relations are shown: inductance emf flux linkage relation and torque emf relation. These two relations are proved using the Chan Series. The inductance emf flux linkage relation links the three motor parameters: inductance, back emf, and flux linkage. The torque emf relation is of practical use because the back emf can be computed from the measured motor torque. Volume under the coenergy surface indicates the motor's size taking into consideration the effects of magnetic flux saturation. The computed volume under the coenergy surface of the motor' is $8.66 \mathrm{JA}$.

Computer simulations of the nonlinear model in the chop, single-chop, and single-pulse modes are obtained. Plots of currents dynamics in these 3 modes are compared to those computed in [19]. The two data sets show good correlation to each other. Also, the torque profile of the motor when in the chop current mode is plotted. This profile is compared to that predicted in [19]. The two profiles show good agreement to each other as well. Thus, a simple nonlinear SRM model has been developed.

\section{REFERENCES.}

[1] P. J. Lawrenson, J. M. Stephenson, P. T. Blenkinsop, J. Corda, and N. N. Fulton, "Variable-speed switched reluctance motors," IEE Proc., vol. 127, pt. b, no. 4, pp. 253-265, Jul. 1980.

[2] J. G. O'Donovan, P. J. Roche, R. G. Kavanagh, M. G. Egan, and J. M. D. Murphy, "Neural network based torque ripple minimisation in a switched reluctance motor," 20th lnt. Conf. on Industrial Electronics, Control and Instrumentation, vol. 2, 1994, p. 1226-1231.

[3] J.W. Finch and H. M. B. Metwally, "Control aspects of brushless drives using switched reluctance motors," 4 th int. Conf. of Power Electronics and Variable-Speed Drives, IEE Conf. Publication no. 324, London, UK, 1990, p. 237-242.

[4] H. H. Moghbelli and M. H. Rashid, "Performance review of ac adjustable drives," Proc. of the IECON' 90, 1990, p. 895-901.

5] 1 . Husain and $M$. Ehsani, "Rotor position sensing in switched reluctance motor drives by measuring mutually coupled induced voltages," IEEE Trans. on Industry Applications, vol. 30, no. 3, pp. 665-670, May 1994.

[6] J. Faiz, J. W. Finch, and H. M. B. Metwally, "A novel switched reluctance motor with multiple teeth per stator pole and comparison 
of such motors," Electric Power Systems Research, vol. 34, pp. 197-203, 1995.

[7] F. Gentili and S. Nicosia, "Observer based control system design for switched reluctance motors," Proc. of the 34th Conf. on Decision and Control, vol. 1, Dec. 1995, p. 115-120.

[8] T. Uematsu and R. S. Wallace, "Design of a $100 \mathrm{KW}$ switched reluctance motor for electric vehicle propulsion," Tenth Annual Applied Power Electronics Conf. and Exposition, vol. 1, 1995, p. 411415.

[9] J. Faiz and J. W. Finch, "Aspects of design optimization for switched reluctance motors, "IEEE Trans. on Energy Conversion, vol. 8, no. 4 pp. 704-713, Dec. 1993

[10] M. Moallem, H. Nikkhajoei, and M. Falahi, "Predicting the performance of a switched reluctance machine using improved magnetic equivalent circuit method," Proc. of the 1995 Int. Conf. on Power Electronics and Drive Systems, vol. 1, 1995, p. 198-201.

[11] D. A. Staton, W. L. Soong, and T. J. E. Miller, "Unified theory of torque production in switched reluctance and synchronous reluctance motors," IEEE Trans. on Industry Applications, vol. 31, iss. 2, pp. 329-337, 1995.

[12] D. A. Staton, R. P. Deodhar, W. L. Soong, and T. J. E. Miller, "Torque prediction using the flux-mmf diagram in ac, dc, and reluctance motors," IEEE Trans. on Industry Applications, vol. 32, no. 1, pp. 180-188, Jan. 1996.

[13] A. V. Radun, "Design considerations for the switched reluctance motor," IEEE Trans. on Industry Applications, vol. 31, iss. 5, pp. 1079-1087, 1995

[14] F. Filicori, C. Guarino Lo Dianco, and A. Tonielli, "Modeling and control strategies for a variable reluctance direct-drive motor," IEEE Trans. on Industrial Electronics, vol. 40, no. 1, pp. 105-115, Feb. 1993.

[15] D. A. Torrey and J. H. Lang, "Modelling a nonlinear variablereluctance motor drive," IEE Proc., vol. 137, pt. b, no. 5, pp. 314-326, Sep. 1990.

[16] T. J. E. Miller and M. McGilp, "Nonlinear theory of the switched reluctance motor for rapid computer-aided design," IEE Proc., vol. 137, pt b no. 6, pp. 337-347, Nov. 1990

[17] J. J. Garside, R. H. Brown, and A. A. Arkadan, "Identification of switched reluctance motor states using application specific artificial neural networks." Proc. of the IEEE Int. Conf. on Industrial Electronics, Control, and Instrumentation (IECON), vol. 2, 1995, p. 1446-1451.

[18] L. A. Belfore and A. A Arkadan, "Modeling faulted switched reluctance motors using evolutionary neural networks," 20th Int. Conf on Industrial Electronics, Control and Instrumentation, vol. 2, 1994, p. 1247-1252

[19] S. K. Panda and G. A. J. Amaratunga, "Waveform detection technique for indirect rotor-position sensing of switched reluctance motor drives - pt. 1: analysis," IEE Proc., pt. b, vol. 140, no. 1, pp. 80 88, Jan. 1993

[20] M. llic'-Spong, R. Marino, S. M. Peresada, and D. G. Taylor, "Feedback linearization control of switched reluctance motors" IEEE Trans. on Automatic Control, vol. ac-32, no. 5, pp. 371-379, May 1987.

[21] L. Ben Amor, L.-A. Dessaint, O. Akhrif, and G. Olivier, "Adaptive feedback linearization for position control of a switched reluctance motor," Int. Journal of Adaptive Control Signal Processing 7, pp. 117136, 1993.

[22] C. Rossi and A. Tonielli, "Feedback linearizing and sliding mode control of a variable reluctance motor," Int. Journal of Control, vol. 60 , no. 4, pp. 543, Oct. 1994.

[23] J. J. Carroll, D. M. Dawson, and P. Vedagarbha, "Experimental verification of adaptive and robust trajectory tracking controllers for switched reluctance motors," Proc. of the 33rd IEEE Conf. on Decision and Control, vol. 2, 1994, p. 1856-1861.

[24] J. J. Carroll, D. M. Dawson, and Z. Qu, "Robust tracking control of a switched reluctance motor turning an inertial load," Proc. of the 1992 American Control Cont. vol. 2, 1992, p. 1520-1522

[25] C. A. Jacobson, A. M. Stankovic, G. Tadmor, and Z. Coric, "A family of robust control strategies for switched reluctance motors," Proc. of the 1995 Int. Conf. on Power Electronics and Drive Systems, vol. 1, 1995, p. 192-197.

[26] J. J. Carroll and D. M. Dawson, "Adaptive tracking control of a switched reluctance motor turning an inertial load," Proc. of the 1993 American Control Conf., vol. 1, 1993, p. 670-674.

[27] L Ben Amor L A Dessaint and $O$. Akhrif, "Adaptive nonlinear torque control of a switched reluctance motor via flux observation," Mathematics and Computers in Simulation, vol. 38, iss. 4-6, pp. 345358, Aug. 1995
[28] A. Lumsdaine and J. H. Lang, "State observers for variablereluctance motors," IEEE Trans. on Industrial Electronics, vol. 37, no. 2, pp. 133-142, Apr. 1990.

[29] P. C. Kjaer, P. Nielsen, L. Andersen, and F. Blaabjerg, "A new energy optimizing control strategy for switched reluctance motors," IEEE Trans. on Industry Applications, vol. 31, iss. 5, pp. 1088-1095, 1995.

[30] D. E. Rumelhart, G. E. Hinton, and R. J. Williams, "Learning internal representations by error propagation, parallel distributed processing," Vol. 1, Explorations in the Microstructure of Cognition: Foundations, Cambridge, Massachusetts: MIT Press, 1986, ch. 8, pp. 318-362.

[31] K. S. Narendra and K. Parthasarathy, "Identification and control of dynamical systems using neural networks," IEEE Trans. on Neural Networks, vol. 1, no. 1, po. 4-27, Mar. 1990

[32] J. T. Oden, Applied Functional Analysis. New Jersey: PrenticeHall, Inc., 1979, pp. 174. 